\title{
AVALIAÇÃO E SIMULAÇÃO DO COMPORTAMENTO DO FOGO EM DIFERENTES FITOFISIONOMIAS DE UMA ÁREA DE MATA ATLÂNTICA DO NORDESTE BRASILEIRO
}

\author{
Benjamin Leonardo Alves White ${ }^{1 *}$; Marcus Vinícius Noronha de Oliveira ${ }^{2}$; Genésio Tâmara Ribeiro ${ }^{3}$ \\ 1* Universidade Federal de Sergipe, Departamento de Biociência, Itabaiana, Sergipe, Brasil - benjmk@ hotmail.com \\ ${ }^{2}$ Secretaria de Estado da Educação, Aracaju, Sergipe, Brasil - mv_bioufs@ @otmail.com \\ ${ }^{3}$ Universidade Federal de Sergipe, Departamento de Engenharia Florestal, São Cristóvão, Sergipe, Brasil - genesiotr@hotmail.com
}

Recebido para publicação: 22/02/2017 - Aceito para publicação: 14/08/2017

\begin{abstract}
Resumo
Incêndios florestais constituem um dos maiores problemas ambientais do mundo moderno. Eles podem reduzir a biodiversidade, contribuir com a emissão de gases do efeito estufa e alterar as propriedades químicas e físicas do solo. Em busca de novos conhecimentos que auxiliem os trabalhos de prevenção e combate aos incêndios, novos estudos vêm sendo desenvolvidos baseando-se na modelagem do comportamento do fogo. O objetivo deste trabalho foi avaliar parâmetros como velocidade de propagação do fogo, comprimento das chamas e consumo do material combustível em diferentes fitofisionomias presentes no Refúgio de Vida Silvestre Mata do Junco, Capela, Sergipe, Brasil. Para tal, foram coletadas amostras de material combustível superficial que foram levadas ao laboratório para realização de 45 queimas experimentais. Os dados obtidos em laboratório foram comparados às simulações realizadas pelos softwares Eucalyptus Fire Safety System e BehavePlus buscando-se avaliar a eficiência dos mesmos. Foram observadas diferenças significativas nos parâmetros do comportamento do fogo entre os ambientes selecionados para o estudo. Nas fitofisionomias de bambuzal e vegetação regenerante, o fogo apresentou maior velocidade de propagação e comprimento das chamas quando comparado com as áreas de mata fechada. O consumo do material combustível foi maior nos bambuzais. Em relação aos softwares utilizados, houveram diferenças significativas entre os valores reais e os simulados por ambos. Os resultados obtidos demostram a necessidade de se construir ou ajustar modelos matemáticos que estimem com maior eficiência o comportamento do fogo a fim de se auxiliar os trabalhos de prevenção e combate.
\end{abstract}

Palavras-chave: Incêndios florestais; BehavePlus; Eucalyptus Fire Safety System.

\begin{abstract}
Evaluation and Simulation of Fire Behavior in Different Vegetation Types in an Atlantic Forest Area of Northeast Brazil. Wildfires are one of the most important environmental problems of the modern world. They represent a threat to the preservation of biodiversity, increase the release of greenhouse gases and change the chemical and physical properties of the soil. The knowledge of how the fire will behave can be used to assist fire prevention and suppression activities, that is why new studies have been done trying to describe and model fire behavior parameters. The aim of this work was to evaluate parameters such as rate of spread, flame length and fuel consumption in different vegetation types from the Mata do Junco Wildlife Refuge, Capela, Sergipe, Brazil. For this purpose, surface fuel load samples were collected in different vegetation types and brought to the laboratory to perform 45 experimental burns. The data from the burns were compared with simulations done in the software Eucalyptus Fire Safety System and BehavePlus in order to assess their efficiency. Significant differences in the fire behavior parameters was verified in the three different vegetation types. In the bamboo fields and regenerating vegetation, the fire had higher rate of spread and flame length when compared with the closed forests. The fuel consumption was greater in the bamboo fields. Significant differences between actual and simulated values for both programs were also observed. The results from this study evidence the need to build or adjust new and more efficient mathematical models in order to improve fire prevention and suppression activities.
\end{abstract}

Keywords: Forest fires; BehavePlus; Eucalyptus Fire Safety System.

\section{INTRODUÇÃO}

Os incêndios florestais constituem um dos maiores problemas ambientais do mundo moderno. Muitas vezes derivados do mau uso do fogo durante práticas agropecuárias, eles põem em risco a biodiversidade de 
áreas naturais protegidas, contribuem para a emissão de gases de efeito estufa e alteram as propriedades físicoquímicas do solo.

Trabalhos realizados por pesquisadores do mundo inteiro têm tentado compreender os fatores que possuem influência direta sobre a ocorrência de incêndios florestais (ANDREU et al., 2012; KREYE et al., 2014; WHITE et al., 2016a). Sabe-se que variáveis climáticas como pluviosidade, velocidade dos ventos, temperatura e umidade relativa do ar estão intrinsecamente relacionadas ao problema (WHITE; RIBEIRO, 2011; SANJUAN et al., 2014; WHITE et al., 2016a). Entretanto, variáveis como quantidade de biomassa disponível, nível de compactação, teor de umidade, relevo, entre outras, também exercem influência na propagação dos incêndios florestais (ROTHERMEL, 1972; SOARES; BATISTA, 2007; WHITE et al., 2016a).

Diante disso, desde a década de 1940, pesquisadores e órgãos ambientais como o United States Department of Agriculture (USDA), por exemplo, vêm desenvolvendo estudos de modelagem do comportamento do fogo através de queimas controladas e simulações em laboratório, para sua melhor compreensão (KOCHANSKI et al., 2013; WHITE et al., 2013a). Resultante desses trabalhos, foi criado o modelo de propagação do fogo superficial proposto por Rothermel (1972), um dos mais aceito e citado na literatura. $\mathrm{O}$ respectivo modelo foi inserido em diversos softwares de modelagem do comportamento do fogo como o BehavePlus (ANDREWS et al., 2003). Nele, é possível obter informações úteis sobre o comportamento do fogo para elaboração de planos operativos de prevenção e combate aos incêndios florestais, tais como: velocidade de propagação, comprimento das chamas, intensidade da linha de fogo, entre outros (WHITE et al., 2013b).

No entanto, os modelos matemáticos utilizados pelos softwares citados foram desenvolvidos em condições climáticas e formações vegetacionais distintas das predominantes no Brasil. Considerando que o clima e as características do material combustível exercem papel fundamental no comportamento do fogo, os respectivos modelos possuem limitações quando utilizados para simular parâmetros inerentes ao comportamento do fogo em condições ambientais diferentes das quais foram desenvolvidos (WHITE et al., 2013b). Considerando essa problemática, White et al. (2016a) criaram um software de avaliação do comportamento do fogo chamado de Eucalyptus Fire Safety System que foi desenvolvido para estimar variáveis do comportamento do fogo em condições de clima tropical. Embora tenha sido criado com base em experimentos realizados apenas em liteira de eucalipto, os parâmetros climáticos sobre o qual seus modelos empíricos foram desenvolvidos são bem próximos dos encontrados em boa parte do litoral Nordestino Brasileiro.

Este trabalho teve como objetivo avaliar o comportamento do fogo, através de queimas controladas em laboratório, em três diferentes fitofisionomias de um remanescente de Mata Atlântica localizado no Refúgio de Vida Silvestre Mata do Junco. Além disso, dois softwares distintos: o Eucalyptus Fire Safety System 1.0 (EFSS) (White et al., 2016a) e o BehavePlus 5.0 (BP) (ANDREWS et al., 2003) foram avaliados com base nos dados experimentais, a fim de refutar ou aceitar a hipótese nula de que ambos os softwares descrevem apropriadamente o comportamento do fogo.

\section{METODOLOGIA}

\section{Caracterização da área de estudo}

A coleta do material combustível foi realizada no Refúgio de Vida Silvestre Mata do Junco (RVSMJ), município de Capela, Sergipe, Brasil $\left(10^{\circ} 32^{\prime}-10^{\circ} 35^{\prime} \mathrm{S} ; 36^{\circ} 59^{\prime}-37^{\circ} 4^{\prime} \mathrm{W}\right)$. Trata-se de um fragmento de Mata Atlântica, com aproximadamente 897 ha, de alto valor biológico para o estado, uma vez que abriga espécies raras, endêmicas e ameaçadas de extinção, como é o caso do macaco-guigó (Calicebus coimbrai) (SANTOS et al., 2007).

O clima da região é considerado megatérmico subúmido com temperaturas médias anuais de $24,9{ }^{\circ} \mathrm{C}$, precipitação média anual em torno de $1372 \mathrm{~mm}$ e chuvas concentradas entre os meses de março e agosto (FONTES, 1998). De acordo com Malta (2011), o RVSMJ apresenta fragmentos típicos de Mata Atlântica de Tabuleiro, encontrando-se bastante descaracterizado não apenas no município de Capela, mas em todo o estado de Sergipe, devido principalmente às transformações históricas causadas pela ação antrópica, especialmente por pastagens e agricultura.

\section{Procedimentos de coleta}

As fitofisionomias de floresta de tabuleiro, pastagens abandonadas e vegetação regenerante (DANTAS et al., 2006) foram selecionadas para a realização deste estudo em função de apresentarem maior área de abrangência na RVSMJ e de estarem próximas às áreas de ocorrência de queima controlada para colheita da cana-de-açúcar (Figura 2). 

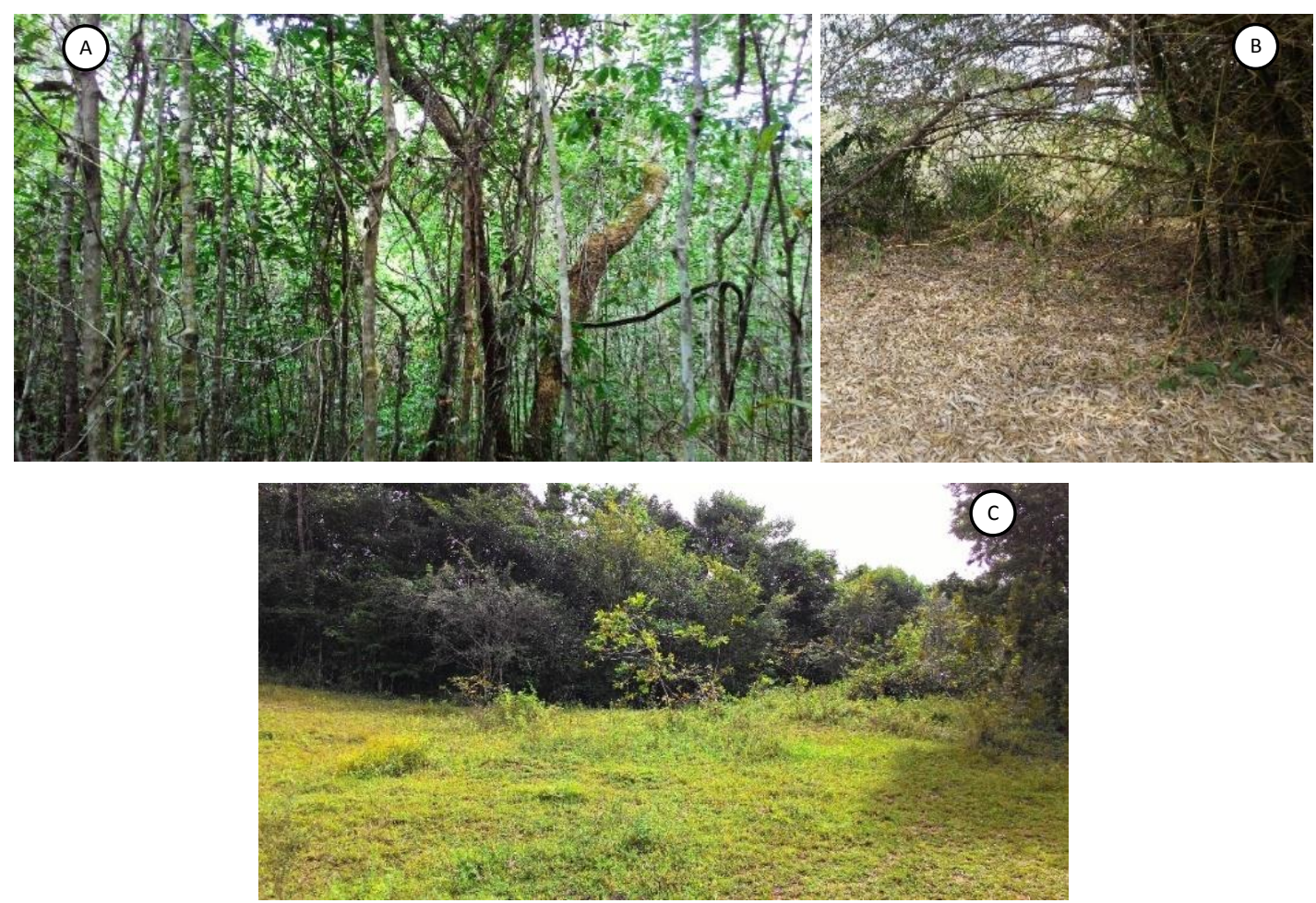

Figura 1. Fitofisionomias do Refúgio da Vida Silvestre Mata do Junco selecionadas para coleta de material combustível e avaliação do comportamento do fogo. A - Floresta de tabuleiro (mata fechada); B Pastagens abandonadas (bambuzal); C - Vegetação regenerante (áreas de transição).

Figure 1. Phytophysiognomies from the Mata do Junco Wildlife Refuge selected to fuel collect and fire behavior analyzes. A - Tableland forest (closed forest); B - Abandoned pastures (bamboo fields); C Regenerating vegetation (transition Area).

As florestas de tabuleiros, neste trabalho denominadas de "mata fechada", caracterizam-se principalmente pela luminosidade reduzida em seu interior devido à alta densidade de sua copa, formada por espécies sucessionais tardias como o ipê-amarelo (Handroanthus chrysotrichus Mart. ex A. DC. Mattos) e o Jatobá (Hymenaea courbaril L.). São florestas bem conservadas com mínima influência antrópica. As áreas de pastagens abandonadas são, neste trabalho, chamadas de "áreas de bambuzais" em função da presença de grande quantidade de bambus da espécie Phylostachys aurea Rivière \& C.Rivière. O bambu que era utilizado para sombreamento das pastagens, com a criação da unidade de conservação e extinção da prática agrícola/pecuária, passou a ocupar amplas áreas. A quantidade de herbáceas e gramíneas é pequena, sendo o solo recoberto principalmente por folhas secas da referida espécie. Por último, a fitofisionomia de vegetação regenerante, chamadas neste trabalho de "áreas de transição", são áreas que foram bastante modificadas pela ação humana e encontram-se em estado de regeneração inicial. Assemelham-se a uma área de ecótono (transição) entre fragmentos florestais, com alta luminosidade e com intenso processo de sucessão ecológica, sendo possível encontrar grande quantidade de poáceas (gramíneas) e ciperáceas.

A coleta do material combustível foi realizada entre os meses de janeiro e outubro de 2015, utilizandose uma moldura quadrada de PVC com dimensões de 1,5 x 1,5 m. Em cada fitofisionomia foram delimitadas 15 parcelas aleatórias onde, através de amostragens destrutivas, toda a biomassa vegetal até 1,8 $\mathrm{m}$ de altura (limite do material combustível superficial) foi coletada, armazenada em sacos de nylon de $50 \mathrm{Kg}$ e imediatamente levada ao laboratório para realização de queimas controladas.

\section{Avaliação do comportamento do fogo}

Para verificar o comportamento do fogo, foram realizadas quinze queimas experimentais em laboratório com o material coletado para cada uma das três fitofisionomias, perfazendo um total de quarenta e cinco queimas. As mesmas foram realizadas em um laboratório montado temporariamente em uma propriedade rural particular próxima à Universidade Federal de Sergipe, Campus Itabaiana.

No laboratório, foi instalada uma mesa de combustão de 1,5 x 1,5 m, cercada por paredes de madeira (2,20 m de comprimento e 1,40 m de altura) com objetivo de padronizar as queimas em relação à direção do

FLORESTA, Curitiba, PR, v. 47, n. 3, p. 247 - 256, jul. / set. 2017.

White, B. L. A.. et al.

ISSN eletrônico 1982-4688

DOI: $10.5380 /$ rf.v47i1.50844 
vento. A mesa de combustão foi construída baseando-se em experimentos realizados por Beutling et al. (2012) e White et al. (2016a). Nela, foram demarcadas quatro linhas de $25 \mathrm{~cm}$ e duas linhas de $12,5 \mathrm{~cm}$. Fotografias digitais e duas réguas de madeira graduadas em $10 \mathrm{~cm}$ foram utilizadas para auxiliarem na determinação do comprimento das chamas com base na inclinação e altura do fogo (Figura 4).
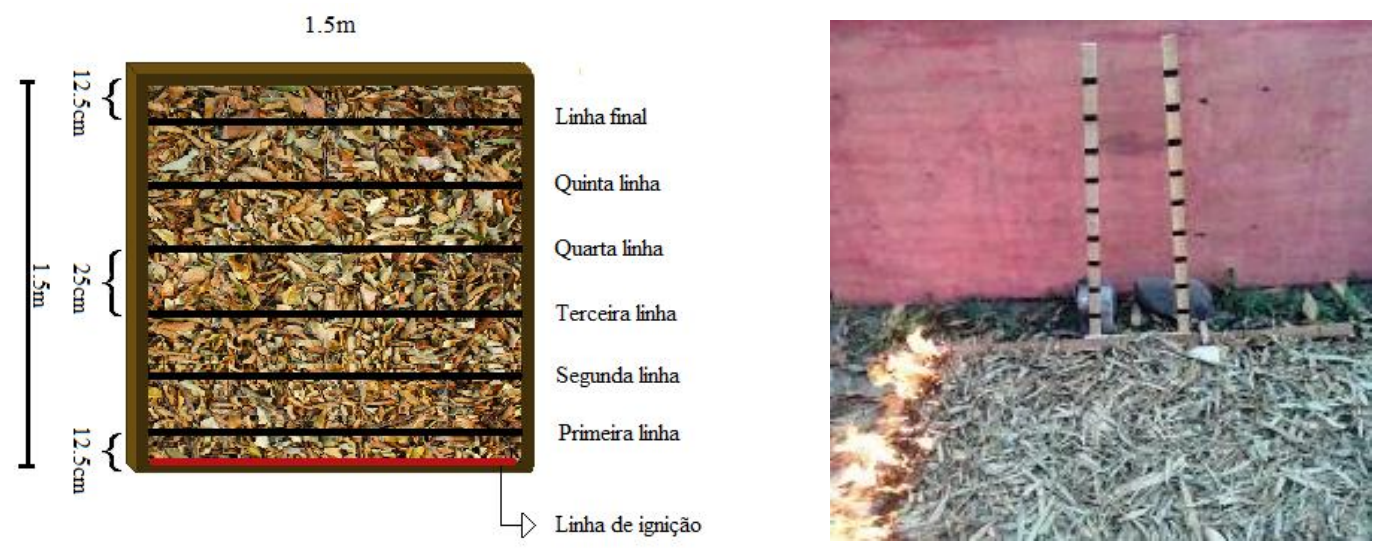

Figura 2. Croqui da mesa de combustão (esquerda) e detalhe das réguas adaptadas para auxiliar na determinação do comprimento das chamas (direita).

Figure 2. Sketch of the combustion table (left) and rulers adapted to estimate the flame length (right).

Apesar do material combustível ter sido transportado do campo ao laboratório, o mesmo foi disposto na mesa de combustão de modo a apresentar as características de carga, espessura e densidade próximas às verificadas em campo para cada fitofisionomia. Os sacos de nylon com a biomassa fresca coletada foram acondicionados e transportados de modo a evitar troca de umidade entre o material e a atmosfera até o momento de sua queima, conservando assim valores referentes ao teor de umidade próximos ao encontrado em campo. Tais procedimentos foram necessários em função da impossibilidade legal de se realizar as queimas experimentais dentro da unidade de conservação.

Após o material combustível ter sido distribuído da maneira mais homogênea possível sobre a mesa de combustão, remontando ao ambiente natural, era iniciada a ignição com auxílio de um queimador pinga-fogo abastecido com querosene, feita sobre a linha de ignição. Quando o fogo atingia a primeira linha $(12,5 \mathrm{~cm}) \mathrm{o}$ cronômetro era acionado, sendo interrompido apenas no momento em que o fogo atingia a linha final, estabelecendo assim a velocidade de propagação do fogo. Nos experimentos em que fogo se extinguiu antes de chegar até a linha final, a velocidade de propagação recebeu o valor de 0 . O comprimento das chamas foi determinado com base na média de 5 medições realizadas no exato momento em que o fogo atingia a segunda, terceira, quarta, quinta e a linha final. Nos experimentos em que o fogo não se propagou até a linha final foi definido o comprimento das chamas com base na média das medições até então realizadas, sendo que o valor 0 foi atribuído somente nos casos em que o fogo não chegou a atingir a segunda linha. Ao término de cada experimento, o material que permanecia sem queimar (residual) era separado e sua massa determinada para avaliar o consumo do material combustível em cada experimento. O consumo do material combustível recebeu o valor de $0 \%$ apenas nos casos em que o fogo se extinguiu antes de ultrapassar a primeira linha.

\section{Simulação do comportamento do fogo}

Os softwares EFSS e BP foram utilizados a fim de simular a velocidade de propagação do fogo, o comprimento das chamas e o consumo do material combustível para posteriormente terem seus resultados comparados com os valores obtidos experimentalmente. O consumo do material combustível foi simulado apenas no EFSS em função do BP não ser capaz de realizar tal função.

No BP foi utilizado o módulo Surface com modelos customizados de material combustível. No caso do EFSS, como foi originalmente construído apenas para simular o comportamento do fogo em liteira de eucalipto, o mesmo não possuí a função de personalizar o modelo de material combustível (WHITE et al., 2016a).

Antes de realizar as queimas experimentais, toda a biomassa fresca (úmida) era separada e pesada em balança de precisão de $0,1 \mathrm{~g}$ de acordo com as classes de diâmetro padronizadas por Rothermel (1972) (Tabela 1). Subamostras de cada classe eram secas em estufa a $100{ }^{\circ} \mathrm{C}$ por $24 \mathrm{~h}$ (MATTHEWS, 2010) para posterior determinação do teor de umidade e peso seco, variáveis obrigatórias para a realização das simulações em ambos os softwares. 
Tabela 1. Classes de material combustível de acordo com Rothermel (1972).

Table 1. Fuel load classes according to Rothermel (1972).

\begin{tabular}{lll}
\hline Categoria & Classes & Descrição \\
\hline \multirow{2}{*}{$\begin{array}{l}\text { Material } \\
\text { Combustível Morto } \\
\end{array}$} & $\begin{array}{l}\text { Material Combustível } \\
\text { Material Combustível } \\
\text { Morto de 10-h de timelag } \\
\text { Material Combustível } \\
\text { Morto de 100-h de timelag }\end{array}$ & Materiais com diâmetro menor ou igual a 0,7 cm; \\
& Material Combustível Vivo & $\begin{array}{l}\text { Materiais vivos não lenhosos de caule fino e flexível, com } 0,71 \text { e 2,5 cm; } \\
\text { aspecto de erva; }\end{array}$ \\
Material & Herbáceo & $\begin{array}{l}\text { Inclui a folhagem viva e pequenos ramos da planta com } \\
\text { diâmetro inferior a 0,7 cm; }\end{array}$ \\
\hline
\end{tabular}

Após o material combustível ter sido distribuído sobre a mesa de combustão, uma trena graduada em centímetros $(\mathrm{cm})$ foi utilizada para mensurar a espessura do leito a partir da média de cinco pontos aleatórios. A velocidade média do vento durante a queima, foi obtida com auxílio de um anemômetro portátil modelo PCI-81. A espessura do leito e velocidade do vento também são parâmetro de entrada obrigatórios para realizar simulações tanto no BP quanto no EFSS.

Demais parâmetros obrigatórios para realizar simulações no BP utilizando-se de modelos customizados de material combustível, foram definidos com base na literatura (SCOTT; BURGAN, 2005; SOARES; BATISTA, 2007; FERNANDES et al., 2011) (Tabela 2).

Tabela 2. Valores referente à área superficial pelo volume do material morto de 1-h de timelag, umidade de extinção do material combustível morto e poder calorífero do material combustível morto utilizados para simular o comportamento do fogo no software BehavePlus.

Table 2. Values from the variables 1-h surface area to volume ratio, dead fuel moisture of extinction and dead fuel heat content used to simulate the fire behavior in the BehavePlus software.

\begin{tabular}{lll}
\hline Parâmetro & Valor & Referência \\
\hline Área superficial pelo volume do material morto de $1 \mathrm{~h}\left(\mathrm{~m}^{2} / \mathrm{m}^{3}\right)$ & 4200 & $\begin{array}{l}\text { Fernandes } \text { et al. (2011) } \\
\text { Scott e Burgan (2005); Soares e } \\
\text { Umidade de extinção do material combustível morto }(\%)\end{array}$ \\
Poder calorífero do material combustível morto (kJ/kg) & 30 & $\begin{array}{l}\text { Batista } \\
\text { Scott e Burgan (2005); Fernandes } \\
\text { et al. (2011) }\end{array}$ \\
\hline
\end{tabular}

\section{Análise estatística}

Os dados obtidos durante as queimas experimentais para cada fitofisionomia foram comparados entre si através da Análise de Variância (ANOVA), seguida do teste de Tukey, com o objetivo de verificar se os parâmetros do comportamento do fogo avaliados apresentaram diferenças significativas nas distintas fitofisionomias. Os mesmos testes estatísticos foram utilizados para comparar os valores simulados através dos softwares Eucalyptus Fire Safety System 1.0 (WHITE et al., 2016a) e do Behaveplus 5.0 (ANDREWS et al., 2003) com os valores experimentais. Todos os testes estatísticos foram realizados ao nível de 5\% de significância com auxílio do software JMP statistical package (versão 10.0, SAS Institute, Cary, NC).

\section{RESULTADOS}

\section{Características do material combustível pré-queima}

Em função dos cuidados tomados para conservar as características originais do material combustível, os valores referente à carga, umidade, espessura e densidade imediatamente antes de queimar encontram-se bem próximos aos verificados em campo. Em todas as fitofisionomias, a maior parte do material combustível disposto na mesa de combustão a ser queimado pertencia à classe morto de 1-h de timelag. Em média, as demais classes juntas tiveram baixa representatividade, contribuindo com apenas $2,9 \%, 9,4 \%$ e $4,5 \%$ da carga total do material combustível paras as fitofisionomias de bambuzal, área de transição e mata fechada, respectivamente. A elevada carga e reduzida espessura do material combustível na fitofisionomia de mata fechada foi responsável por um valor de densidade consideravelmente superior às demais vegetações. Os maiores valores referente ao teor de umidade também foram verificados nas matas fechadas (Tabela 3).

FLORESTA, Curitiba, PR, v. 47, n. 3, p. 247 - 256, jul. / set. 2017

White, B. L. A.. et al.

ISSN eletrônico 1982-4688

DOI: $10.5380 /$ rf.v47i1.50844 
Tabela 3. Valores médios referente às características do material combustível pré-queima (carga do MC morto de 1-h de timelag, carga total, espessura do leito, densidade do leito e teor de umidade) das três distintas fitofisionomias e referente à velocidade do vento registrada durante os experimentos.

Table 3. Mean values from the pre-burning characteristics of the fuel (1-h timelag dead fuel load, total load, bed depth, bed bulk density and moisture content) of the three distinct phytophysiognomies and from the wind speed recorded during the experiments.

\begin{tabular}{lccc}
\hline Parâmetros & Bambuzal & $\begin{array}{c}\text { Fitofisionomia } \\
\text { Área de Transição }\end{array}$ & Mata Fechada \\
\hline Carga do MC morto de 1-h de timelag (t/ha) & 7.37 & 9.98 & 20.55 \\
Carga Total (t/ha) & 7.59 & 11.01 & 21.51 \\
Espessura (m) & 0.046 & 0.034 & 0.030 \\
Densidade do leito $\left(\mathrm{kg} / \mathrm{m}^{3}\right)$ & 17.56 & 50.76 & 79.93 \\
Umidade do MC $(\%)$ & 15.91 & 16.02 & 23.36 \\
Velocidade do Vento $(\mathrm{km} / \mathrm{h})$ & 7.47 & 8.8 & 7.63 \\
\hline
\end{tabular}

LEGENDA: MC - Material Combustível.

\section{Avaliação do comportamento do fogo experimental}

Com base no teste ANOVA, foi verificada a existência de diferença significativa na velocidade de propagação do fogo $(\mathrm{F}=6,14 ; \mathrm{p}<0,01)$; no comprimento das chamas $(\mathrm{F}=4,89 ; \mathrm{p}=0,01)$ e no consumo do material combustível $(\mathrm{F}=14,13 ; \mathrm{p}<0,01)$ entre as três fitofisionomias estudadas. $\mathrm{O}$ teste Tukey classificou as variáveis avaliadas em três grupos distintos: A, B e C (Tabela 4).

Tabela 4. Comparação entre as médias das variáveis do comportamento do fogo avaliados nas distintas fitofisionomias do Refúgio de Vida Silvestre Mata do Junco.

Table 4. Comparison between the mean of the fire behavior parameters evaluated in the different phytophysiognomies of the Mata do Junco Wildlife Refuge.

\begin{tabular}{lccc}
\hline Parâmetros & Bambuzal & $\begin{array}{c}\text { Fitofisionomia } \\
\text { Área de Transição }\end{array}$ & Mata Fechada \\
\hline $\mathrm{V}(\mathrm{m} / \mathrm{min})$ & $1,15( \pm 0,84) \mathrm{A}$ & $1,90( \pm 2,35) \mathrm{A}$ & $0,00 \mathrm{~B}$ \\
$\mathrm{C}(\mathrm{m})$ & $0,31( \pm 0,20) \mathrm{A}$ & $0,23( \pm 0,05) \mathrm{AB}$ & $0,17( \pm 0,05) \mathrm{B}$ \\
$\mathrm{CM}(\%)$ & $61,25( \pm 34,9) \mathrm{A}$ & $37,26( \pm 32,01) \mathrm{B}$ & $5,45( \pm 2,66) \mathrm{C}$ \\
\hline
\end{tabular}

LEGENDA: V - Velocidade de propagação do fogo; C - Comprimento das chamas; CM -

Consumo do material combustível; \pm - Desvio padrão.

*Letras maiúsculas comparam as fitofisionomias (linhas);

*Valores seguidos da mesma letra não diferem estatisticamente entre si a 5\% de

significância, pelo teste de Tukey.

A velocidade de propagação e o comprimento das chamas não diferiram significativamente entre as fitofisionomias de Bambuzal e de Transição, no entanto, a velocidade de propagação nas áreas de Mata Fechada diferiu significativamente das mesmas. O comprimento das chamas na Mata Fechada também foi significativamente diferente quando comparado com a área de Bambuzal, porém, não quando comparado com a Área de Transição. No que diz respeito ao consumo do material combustível, todas as fitofisionomias diferiram entre si, sendo a área de Bambuzal com maior consumo, seguida da Área de Transição.

\section{Comparação dos parâmetros de comportamento do fogo entre os softwares}

Dentre as três variáveis do comportamento do fogo avaliadas, apenas a velocidade de propagação do fogo na fitofisionomia Bambuzal apresentou valores simulados, em ambos os softwares, e experimentais (reais) não significativamente diferentes quando comparados entre si $(F=0,39 ; p=0,68)$. Em todas as outras situações apenas um ou nenhum dos softwares apresentou valores simulados não estatisticamente diferentes dos valores reais (Tabela 5).

A velocidade real de propagação do fogo na Mata Fechada não foi significativamente diferente dos valores simulados pelo BP, porém, diferiu dos valores simulados pelo EFSS. Já nas Áreas de Transição ocorreu o inverso, sendo os valores reais não significativamente diferentes dos valores simulados pelo EFSS, porém, distintos dos simulados pelo BP.

Tratando-se do comprimento das chamas, diferenças significativas também foram observadas. Na fitofisionomia de Mata Fechada, por exemplo, os valores experimentais e simulados diferiram em ambas as simulações, sendo que o EFSS superestimou os valores e o BP subestimou. Na área de Bambuzal e de Transição, os valores simulados pelo BP não apresentaram diferença significativa quando comparado aos valores reais, porém os valores simulados pelo EFSS foram superestimados. 
Tabela 5. Valores médios dos parâmetros do comportamento do fogo (velocidade de propagação, comprimento das chamas e consumo do material combustível) reais e simulados com o BehavePlus e com o Ecalyptus Fire Safety System nas três distintas fitofisionomias do Refúgio da Vida Silvestre Mata do Junco.

Table 5. Mean values of real and simulated fire behavior parameters (rate of spread, flame length and fuel consumption) with BehavePlus and Ecalyptus Fire Safety System in the three distinct phytophysiognomies of the Mata do Junco Wildlife Refuge.

\begin{tabular}{ccccccccc}
\hline \multirow{2}{*}{ Fitofisionomias } & \multicolumn{3}{c}{ Parâmetros do comportamento do fogo } & \multicolumn{3}{c}{ C (m) } & \multicolumn{2}{c}{ CM (\%) } \\
& Real & EFSS & BP & Real & EFSS & BP & Real & EFSS \\
\hline Bambuzal & $1,148 \mathrm{~A}$ & $0,969 \mathrm{~A}$ & $0,888 \mathrm{~A}$ & $0,309 \mathrm{~B}$ & $0,646 \mathrm{~A}$ & $0,461 \mathrm{AB}$ & $61,250 \mathrm{~A}$ & $81,717 \mathrm{~A}$ \\
Área de Transição & $1,898 \mathrm{~A}$ & $0,731 \mathrm{AB}$ & $0,501 \mathrm{~B}$ & $0,225 \mathrm{~B}$ & $0,613 \mathrm{~A}$ & $0,245 \mathrm{~B}$ & $37,260 \mathrm{~B}$ & $70,699 \mathrm{~A}$ \\
Mata Fechada & $0,000 \mathrm{~B}$ & $0,272 \mathrm{~A}$ & $0,018 \mathrm{~B}$ & $0,165 \mathrm{~B}$ & $0,413 \mathrm{~A}$ & $0,016 \mathrm{C}$ & $5,451 \mathrm{~B}$ & $60,004 \mathrm{~A}$ \\
\hline
\end{tabular}

LEGENDA: V - Velocidade de propagação do fogo; C - Comprimento das chamas; CM - Consumo do material combustível; EFSS Eucalyptus Fire Safety System; BP - BehavePlus.

*Letras maiúsculas comparam valores reais e valores simulados (linhas);

* Valores seguidos da mesma letra não diferentes estatisticamente a 5\% de significância, pelo Teste de Tukey.

Em relação ao consumo de material combustível, os resultados apontaram diferenças significativas nas fitofisionomias de Mata Fechada e de Área de Transição. No Bambuzal os valores reais e simulados não apresentaram diferença significativa.

Com base na análise dos valores simulados e reais, pode-se concluir que o maior problema encontrado no EFSS foi que o mesmo superestimou os valores das variáveis do comportamento do fogo avaliadas. Das 135 simulações realizadas neste software (15 para cada uma das 3 variáveis do comportamento do fogo nas 3 fitofisionomias distintas), 109 foram superestimadas (81\%), 21 subestimadas (15\%) e 5 acertos (4\%). Já o maior problema no BP foi que o mesmo subestimou os valores reais. Das 90 simulações realizadas neste software (15 para cada uma das 2 variáveis do comportamento do fogo nas 3 fitofisionomias), 40 foram subestimadas (44\%), 23 superestimadas (26\%) e 27 acertos (30\%). É importante mencionar que dos 27 acertos que o BP obteve, 14 deles, ou seja, mais da metade, foram referentes à velocidade de propagação do fogo na Mata Fechada. Nesta fitofisionomia, o fogo não conseguiu se propagar até o final da mesa de combustão e obteve o valor zero para a respectiva variável em todos os experimentos.

\section{DISCUSSÕES}

As diferenças observadas no comportamento do fogo nas distintas fitofisionomias deve-se, principalmente, às características do material combustível, já que o relevo foi o mesmo e as condições climáticas bastante similares durante a execução das queimas controladas. Nas áreas de Mata Fechada, por exemplo, o teor médio de umidade do material combustível e a densidade do leito apresentaram valores bem mais altos que nas Áreas de Transição e nos Bambuzais. Estes elevados valores justificam a baixa velocidade de propagação, comprimento das chamas e consumo do material combustível, já que, quanto maior o teor de umidade e mais compactado o leito do material combustível, maior é a dificuldade do fogo se propagar (ROTHERMEL, 1972; SOARES; BATISTA, 2007; FERNANDES; LOUREIRO, 2013; WHITE et al., 2016a). O elevado teor de umidade no material combustível reduz a eficiência termal, já que será necessário um elevado gasto de energia para inicialmente evaporar a água e, a partir de então, dar-se origem o processo de combustão (MATTHEWS, 2014; WHITE et al., 2016a). Já combustíveis mais compactados apresentam uma menor relação área superficial/volume, o que ocasiona menor transferência de calor durante o processo de combustão. Além disso, a passagem do vento por entre o material combustível é inferior em leitos mais densos, o que dificulta ainda mais a propagação do fogo (ROTHERMEL, 1972; SOARES; BATISTA, 2007; WHITE et al., 2016a).

As diferenças observadas entre os valores experimentais e simulados, e entre as simulações dos programas, se devem aos distintos modelos matemáticos utilizados por cada software. O EFSS, por exemplo, foi construído a partir de simulações com liteira de eucalipto. De acordo com Soares e Batista (2007) e Fernandes et al. (2011) algumas espécies de eucalipto são extremamente inflamáveis e apresentam um alto poder calorífero em função de suas características físicas e composição química, características essas não presentes em vegetações típicas de biomas de Mata Atlântica. Por esse motivo, o EFSS superestimou o comportamento do fogo na maioria de suas simulações, principalmente na fitofisionomia de mata fechada.

O software BP não foi produzido para situações tão específicas, como o foi o EFSS. Nele existem 56 modelos padrões de material combustível, descritos por Scott e Burgan (2005), o que de certa forma reduz o esforço do pesquisador nos trabalhos de campo para a determinação das variáveis de entrada, tornando-o, assim, o mais utilizado entre gestores de recursos florestais no mundo inteiro (ANDREWS, 2010). Entretanto, vale

FLORESTA, Curitiba, PR, v. 47, n. 3, p. 247 - 256, jul. / set. 2017

White, B. L. A.. et al.

ISSN eletrônico 1982-4688

DOI: $10.5380 /$ rf.v47i1.50844 
ressaltar que os modelos padrões do BP foram produzidos com intuito de caracterizar as fitofisionomias norteamericanas e não as brasileiras. Em função disso, diversos trabalhos apontam para a necessidade de customização de modelos de material combustível, com dados obtidos durante a realização dos experimentos (WHITE et al., 2013b).

O presente trabalho realizou as simulações no BP utilizando-se de modelos customizados do material combustível, porém, ainda assim, 70\% das simulações falharam em descrever o comportamento do fogo real, sendo que deste percentual, $44 \%$ foram simulações que subestimaram a velocidade de propagação e o comprimento das chamas. Este resultado é de certa forma preocupante, já que subestimativas do comportamento do fogo oferecem um maior risco de vida ao brigadista responsável pelo seu combate. Esta tendência do modelo de Rothermel (modelo matemático utilizado pelo BP) em subestimar a velocidade de propagação do fogo já foi reportada por diversos outros autores como, por exemplo, McCaw (1995) em vegetação arbustiva na Austrália; Stephens et al. (2008) e Weise et al. (2016) em vegetações na Califórnia; e, White et al. (2016b) em liteira de eucalipto no litoral norte da Bahia, Brasil. De acordo com White et al. (2013b) em um trabalho de revisão da literatura sobre o uso do BP, a maioria das publicações afirmam que este software subestimou a velocidade de propagação e o comprimento das chamas das queimas reais.

É importante salientar que o fogo é um evento bastante dinâmico devido a heterogeneidade da estrutura do leito do material combustível e de mudanças na velocidade do vento. Sendo assim, é impossível que um modelo matemático de previsão do comportamento do fogo tenha $100 \%$ de acerto durante suas simulações. Infelizmente, ainda não existe um valor médio do que seria um erro aceitável para simulações envolvendo a estimativa de parâmetros relativo ao comportamento do fogo (WHITE et al., 2016b). De acordo com os mesmos autores, as simulações devem ser avaliadas somente por pessoas experientes em pesquisa ou manejo do fogo e que saibam quando os dados gerados são ou não condizentes com as características do fogo que serão observadas na natureza.

Os resultados obtidos através deste estudo não permitem concluir que o BP é mais eficiente que o EFSS ou vice-versa. A escolha do pesquisador em se utilizar um ou outro software deve estar intrinsecamente relacionada às condições climatológicas do local e ao tipo de material combustível utilizado. No entanto, é imprescindível que o utilizador tenha ciência das limitações e dos possíveis erros proveniente das simulações. É essencial que novos estudos que busquem a construção ou ajuste de modelos matemáticos capazes de avaliar com precisão o comportamento do fogo em diferentes biomas brasileiros sejam realizados. O conhecimento de como o fogo irá se comportar constitui uma das principais estratégias para o delineamento de eficientes medidas de prevenção e combate ao fogo.

\section{CONCLUSÕES}

- Devido às distintas características do material combustível, o fogo se propagou com maior facilidade nas fitofisionomias área de transição e bambuzal. Na mata fechada o fogo não conseguiu se propagar com eficiência em nenhum dos experimentos, demonstrando assim que a alteração antrópica de ecossistemas de Mata Atlântica conservados contribui para o aumento do risco de incêndio.

- Com relação às simulações realizadas no BehavePlus e no Eucalyptus Fire Safety System, ambos se mostraram pouco eficientes em estimar o comportamento do fogo. No geral o EFSS superestimou o comportamento do fogo, enquanto que o BP subestimou.

- É essencial o desenvolvimento de novos estudos que busquem a avaliação/criação/ajuste de modelos matemáticos de previsão do comportamento do fogo para formações vegetacionais tipicamente brasileiras a fim de se aprimorar as atividades de prevenção e combate aos incêndios florestais.

\section{AGRADECIMENTOS}

À FAPITEC/SE e ao CNPq pelo financiamento desta pesquisa.

\section{REFERÊNCIAS}

ANDREU, A. G.; SHEA, D.; PARRESOL, B. R.; OTTMAR, R. D. Evaluating fuel complexes for fire hazard mitigation planning in the southeastern United States. Forest Ecology and Management, Amsterdam, v. 273, p. 4-16, 2012.

ANDREWS, P. L. Do you Behave? - Application of the BehavePlus Fire Modeling System. In: 3rd Fire Behavior and Fuels Conference. Proceedings... Spokane, 2010. 17p. 
ANDREWS, P. L.; BEVINS, C. D.; SELI, R. C. BehavePlus Fire Modeling System Version 2.0 User's Guide. USDA Forest Service, Ogden, 2003. 133p. (General Technical Report RMRS-GTR-106WWW).

BEUTLING, A.; BATISTA, A. C.; SOARES, R. V. Fire behavior modeling based on simulated field plots. Forest Fire, London, v. 158, p. 27-37, 2012.

DANTAS, T. V. P.; RIBEIRO, A. S.; NASCIMENTO-JÚNIOR, J. E.; MACHADO, A.; CRISTINA, K.; SANTOS, C. S. Caracterização florística. In: Secretaria de Estado do Meio Ambiente e dos Recursos Hídricos (Org.). Estudo técnico para a criação do Refúgio de Vida Silvestre da Mata do Junco, Capela, Sergipe. UFS, São Cristóvão, 2007.

FERNANDES, P. A. M.; LOUREIRO, C. Fine fuels consumption and $\mathrm{CO}^{2}$ emissions from surface fire experiments in maritime pine stands in northern Portugal. Forest ecology and management, Amsterdam, v. 291, p. 344-356, 2013.

FERNANDES P. A. M.; LOUREIRO, C.; PALHEIRO, P.; VALE-GONÇALVES, H.; FERNANDES, M. M.; CRUZ, M. G. Fuels and fire hazard in blue gum (Eucalyptus globulus) stands in Portugal. Boletín del CIDEU, Huelva, v. 10, p. 53-61, 2011.

FONTES, A. L. Zoneamento Geoambiental da Bacia do Rio Japaratuba. In: DINIZ, A. F.; FRANÇA, V. L. A. (Org.). Capítulos de Geografia Nordestina. 1ed. Aracaju: NPGEO-UFS, v. 1, p. 220-245, 1998.

KOCHANSKI, A. K.; JENKINS, M. A.; MANDEL, J.; BEEZLEY, J. D.; KRUEGER, S. K. Real time simulation of 2007 Santa Ana fires. Forest Ecology and Management, Amsterdam, v. 294, p. 136-149, 2013.

KREYE, J. K.; BREWER, N. W.; MORGAN, P.; VARNER, J. M.; SMITH, A. M. S.; HOFFMAN, C. M.; OTTMAR, R. D. Fire behavior in masticated fuels: A review. Forest Ecology and Management, Amsterdam, v. 314, p. 193-207, 2014.

MALTA, J. A. O; SOUZA, H. T. R. de; SOUZA, R. M e. A contraditória relação sociedade-natureza em espaços territoriais protegidos - Mata do Junco, Capela/SE. Geografia em questão, Marechal Cândido Rondon, v. 4, n. 1, p. 126-152, 2011.

MCCAW, W. L.; BURROWS, N. D.; FRIEND, G. R.; GILL, A. M. Predicting fire spread in Western Australian mallee-heath. CALMScience Supplement, Como, v. 4, p. 35-42, 1995.

MATTHEWS, S. Effect of drying temperature on fuel moisture content measurements. International Journal of Wildland Fire, Clayton, v. 19, p. 800-802, 2010.

MATTHEWS, S. Dead fuel moisture research: 1991-2012. International Journal of Wildland Fire, Clayton, v. 23, n. 1, p. 78-92, 2014.

ROTHERMEL, R. C. A mathematical model for predicting fire spread in wildland fuels. USDA Forest Service, Intermountain Forest and Range Experiment Station, Ogden, 1972. 40p. (Research Paper INT-115).

SANJUAN, G.; BRUN, C.; MARGALEF, T.; CORTÉS, A. Wind field uncertainty in Forest fire propagation prediction. Procedia Computer Science, Amsterdam, v. 29, p. 1535-1545, 2014.

SANTOS, M. J. S.; SOUZA, H. T. R.; SOUZA, R. M. Biomonitoramento através de indicadores ambientais abióticos - Mata do Junco (Capela-SE). Scientia Plena, São Cristóvão, v. 3, n. 5, p. 142-151, 2007.

SCOTT, J. H.; BURGAN, R. E. Standard fire behavior fuel models: a comprehensive set for use with Rothermel's surface fire spread model. USDA Forest Service, Rocky Mountain Research Station, Fort Collins, 2005. 72p. (General Technical Report RMRS-GTR-153).

STEPHENS, S. L.; WEISE, D. R.; FRY, D. L.; KEIFFER, R. J.; DAWSON, J.; KOO, E.; POTTS, J.; PAGNI, P. J. Measuring the rate of spread of chaparral prescribed fires in Northern California. Fire Ecology, Eugene, v. 4, n. 1, p. 74-86, 2008.

WEISE, D. R.; KOO, E.; ZHOU, X.; MAHALINGAM, S.; MORANDINI, F.; BALBI, J. H. Fire spread in chaparral - a comparison of laboratory data and model predictions in burning live fuels. International Journal of Wildland Fire, Clayton, v. 25, n. 9, p. 980-994, 2016. 
WHITE, B. L. A.; RIBEIRO, A. S. Análise da precipitação e sua influência na ocorrência de incêndios florestais no Parque Nacional Serra de Itabaiana, Sergipe, Brasil. Revista Ambiente \& Água, Taubaté, v. 6, n. 1, p. 148156, 2011.

WHITE, B. L. A.; RIBEIRO, A. S.; RIBEIRO, G. T.; SOUZA, R. M. Building fuel models and simulating their surface fire behavior in the "Serra de Itabaiana" National Park, Sergipe, Brazil. Floresta, Curitiba, v. 43, n. 1, p. 27-38, 2013a.

WHITE, B. L. A.; RIBEIRO, G. T.; SOUZA, R. M. O uso do BehavePlus como ferramenta para modelagem do comportamento e efeito do fogo. Pesquisa Florestal Brasileira, Colombo, v. 33, n. 73, p. 73-84, 2013 b.

WHITE, B. L. A.; WHITE, L. A. S.; RIBEIRO, G. T.; SOUZA, R. M. Empirical models for describing fire behavior in Brazilian commercial eucalypt plantations. CERNE, Lavras, v. 22, n. 4, p. 397-406, $2016 a$.

WHITE, B. L. A.; WHITE, L. A. S.; RIBEIRO, G. T.; SOUZA, R. M. Fire behavior predicting models efficiency in Brazilian commercial eucalypt plantations. CERNE, Lavras, v. 22, n. 4, p. 389-396, 2016 b. 